\title{
"Am I Really Good Enough?": Black and Latinx Experiences with Faculty Development
}

\author{
Sylk Sotto-Santiago
}

\begin{abstract}
This study focuses on the experiences of Black and Latinx faculty in academic medicine in relation to their educational and faculty development. Narratives by participants reflect on their career path and refer to faculty development programs as valuable but also as dominant group-centric, counter to their cultural backgrounds and the underrepresented faculty experience. Findings reveal the need for faculty development to be spaces for affirmation, validation, and accountability and suggest the need for tailored programs. Furthermore, implications on the research and practice of faculty affairs within higher education and academic medicine are outlined.
\end{abstract}

Keywords: underrepresented faculty, minoritized, educational development

Educational development in academic medicine strives to provide faculty with the knowledge, tools, and skills to succeed at the institution. Such efforts attempt to assist faculty in medicine in their work in the classroom and in the laboratory as well as by the patient's bedside. The academic medicine environment can be challenging given demands for increased clinical productivity, multidisciplinary 
approaches to science and education, innovation beyond case-based learning, attention to population health, and accountability through curriculum reform (Irby \& Wilkerson, 2003). These demands push educational developers to recognize that faculty development needs in academic medicine include helping faculty recognize the impact of climate on the learning environment, develop leadership skills so they can create and direct multidisciplinary courses, efficiently use modern instructional technology, and develop expertise in new forms of learning assessment as well as broader faculty development needs such as grant writing, public speaking, and wellness (Irby \& Wilkerson, 2003).

There are diverse options and opportunities for faculty development in academic medicine. For the purposes of this article, faculty development is defined as offerings that include teaching and educational development as well as professional and career development. These programs largely focus on activities critical to higher education and academic medicine, such as teaching, research funding and support, and academic writing. Furthermore, within academic medicine, faculty development offices also engaged in work related to the career development of faculty, such as leadership programs and activities designed to assist faculty with the promotion and/or tenure process.

As noted in the literature, underrepresented faculty (URF) face a number of challenges and barriers within academia. For example, women and URF members experience a lack of supportive professional networks and acknowledge that their networks have been less effective in helping them build their careers and professional reputations. Both groups are also more involved in teaching and service activities than their male and White colleagues (Tierney \& Rhoads, 1993; Laden \& Hagedorn, 2000; Hartlep \& Ball, 2019; Social Sciences Feminist Network Research Interest Group, 2017; Stanley, 2006a). As such, the need for faculty development is even greater among URF members. This qualitative case study explored the experiences and perspectives of Black and Latinx faculty in academic medicine, with specific attention on their experiences with faculty and educational development programs, and their perspectives about their own development needs. 


\section{Literature Review}

In order to ensure successful recruitment, retention, and advancement of URF, medical schools have implemented robust development programs. There is strong evidence to suggest that such programs, along with mentoring programs, increase retention, productivity, and promotion for URF in academic medicine (Rodríguez et al., 2014). Rodríguez et al. (2014) identified several tools that successful faculty development programs use: effective and frequent mentoring; focused instruction on clinical, teaching, and research skills; regular networking opportunities; reduction of administrative or clinical expectations to facilitate scholarly activities that lead to promotion and tenure; institutional seed money for pilot projects; and promotional weight given to institutional service and community service. Similarly, Daley et al. (2011)identified "ingredients" for successful faculty development programs: clearly setting program goals and content, mentoring and coaching, providing a conducive environment, and sustaining support. Yet scholars have found that there are not enough tailored faculty development programs for URF (Rodríguez et al., 2014; Sotto-Santiago et al., 2019).

It is also important to note that scholars have argued that the presence of a "minority faculty development program" was not associated with greater URF representation, recruitment, or promotion, but the intensity of the programs is what matters (Guevara et al., 2013). In this regard, Palmer et al. (2011) measured the effectiveness of faculty development programs beyond participation, reporting that the most rigorous programs were structured as part-time with a fellowship style component (Palmer et al., 2011). Also, successful programs for URF reinforce what academic medical centers measure as the criteria for promotion and tenure: recognition as great educators, significant publications, and significant research funding.

Educational development programs are clearly necessary for career promotion, ensuring tenure, and reaching leadership positions. However, the literature suggests that URF continue to face advancement 
barriers due to limited access to role models and networks that support their career progress as well as institutional failures in understanding the unique demands, pressures, and environments navigated by women and underrepresented faculty (Tuitt, 2010).

URF contribute in unique ways to teaching and learning, especially in inclusive and diverse contexts (Daufin, 2001; Tuitt et al., 2009). They also contribute to the academic mission, playing a pivotal part in role modeling, improving underrepresented student access to higher education, and enhancing race relations (Daufin, 2001; Stanley, 2006b). However, URF face difficulties with remaining in academia, just as underrepresented students have trouble remaining on college campuses (Campbell \& Rodríguez, 2013). The reasons URF faculty leave academic medicine and higher education include isolation; stereotyping, racism, and lack of mentorship, advisement, and support; financial concerns; and inadequate organizational structures that work against equity (Campbell \& Rodríguez, 2013; Thompson \& Louque, 2005). Campbell and Rodríguez (2013) estimate that "there is an $80 \%$ overlap of reasons for minority [sic] students' departure from undergraduate education and reasons for minority [sic] faculty members' difficulties remaining in academic medicine" (p. 1056).

Furthermore, scholars have shown that there are intersections and commonalities between the documented experiences of women and other URF (Cropsey et al., 2008; Jayakumar et al., 2009; Tierney \& Rhoads, 1993; Trower \& Chait, 2002; Turner et al., 1999). For example, Pololi et al. (2012) found that stereotype threat contributes to low selfconfidence and self-efficacy, lack of sponsorship, and unconscious bias when it comes to issues of gender in academic medicine. Stereotype threat refers to the fear of confirming a negative stereotype about our own social group in our words and actions (Steele \& Aronson, 1995; Sotto-Santiago, 2019).

Daley et al. (2011) along with Cohen (1998) have written about the many obstacles that URF face including the disproportionate obligation to serve on time-consuming committees, commitment to mentor students with complicated nonacademic problems, and participation 
in community service. URF in medicine often face added demands to tutor, mentor, remediate, and encourage underrepresented students, although the effort dedicated to such pursuits may receive little recognition (Bergen, 2000; Stanley, 2006a). In addition, URF in academic medicine report being more dissatisfied with their careers and are more likely to report wanting to leave academic medicine within five years, as compared to majority faculty members (Cohen, 1998).

The complex organizational structure of academic medicine can be difficult to succinctly capture as it does differ from typical institutions of higher education. The organizational structure of academic medicine has been generally established in alignment with its tripartite mission of clinical practice, research, and education. Therefore, it is usually comprised of a medical school including other forms of allied health schools, a teaching hospital, and a physician practice group (Cole et al., 2009). Adding to the complexity, each academic medicine center operates in a unique environment often different from that of its flagship institution (Barrett, 2008).

Scholars have shown that within academic medicine's culture is a misalignment between the faculty's own values and perceived institutional values (Pololi et al., 2009). Academic medicine's culture is one of self-promotion; faculty have expressed their distaste of an environment that requires them "to brag" about themselves and that this behavior differs from their own values of being humble and more dedicated to achieving good than to personal aggrandizement (Pololi et al., 2009). Other scholars have suggested that academic medical centers may be described as having a "conflict-laden" culture, in which competition and the associated struggle to remain "on top" are a way of life (Cole et al., 2009, p. 115). The environment around compensation has been described by some faculty as a "You eat what you kill" model (Cole et al., 2009, p. 115). This model gives insight to a highly competitive environment that rewards an overly aggressive approach to performance and generating one's own salary funding.

There are additional realities when considering URF teaching and educational development. Most development programs don't address 
how institution may expect more of women and/or URF professors; how there are higher expectations for women faculty; how women faculty are expected to be more available and nurturing; how Black and Latinx faculty must prove their knowledge and competence in ways that majority White faculty do not; and how Black and Latinx faculty receive lower student evaluation scores than do White and Asian faculty (Arbuckle \& Williams, 2003; Griffin \& Reddick, 2011; Harlow, 2003; Sprague \& Massoni, 2005). Salazar et al. (2010) also highlighted the challenges for classroom implementations and encourage educational developers to work more to support educational practices for inclusive excellence (IE). Successful practices will also create supportive faculty environments. Furthermore, the authors highlighted how leaders in the academy need to enhance their understanding of the classroom experiences of URF and consider developing programs that address various challenges, including intolerance. The authors stated, "Then and only then will teaching while Black and Brown cease to feel like teaching in the line of fire" (p. 73).

\section{Methods}

This study focuses on the experiences of Black and Latinx faculty (BLF) in academic medicine in relation to their faculty and educational development. The purpose of this study was to address two research questions: What experiences do BLF have with faculty development programs? And what are their perspectives on faculty development programs with respect to their own needs?

\section{Framework}

The concept of IE, which is designed to help colleges and universities integrate diversity, equity, and educational quality efforts into their missions and operations, is used to frame this study. The Association of American Colleges and Universities (AAC\&U) presented the vision 
and practice of IE and called for institutions of higher education to address diversity, inclusion, and equity. IE proposes an active process through which institutions achieve excellence in learning, teaching, student development, institutional functioning, and engagement in local and global communities (AAC\&U, n.d.). One of the IE goals is to develop "equity-minded practitioners" who are willing to engage in the necessary conversations and decision-making to effect transformational change through the principles of diversity, inclusion, equity, and equity mindedness. Institutions have operationalized IE in several ways, including the overarching goals of building a diverse community, creating a supportive climate for diversity, structuring for change, and serving the public good (University of Denver, n.d.).

However, only a handful of academic medical centers have embraced the IE model thus far, including Virginia Commonwealth University, Case Western Reserve University, University of Missouri, and Drexel University, among a few others. Among academic medical centers, Virginia Commonwealth University committed to intentionally integrating IE to adhere to a three-dimensional model of social identity, core areas, and focus groups (VCU, n.d.). Drexel University has implemented the model by creating four subcommittees focusing on target constituents: faculty diversity, professional staff, student diversity, and community outreach (Drexel University, n.d.). The lack of broader IE implementation in academic medicine may demonstrate perceived limited options of conceptual frameworks that apply to academic medicine, the complexity of developing an IE model within medicine, and the complexity of academic medical centers climates and cultures.

By making equity, inclusion, and diversity part of the strategic approach to transformational change, practitioners can also evaluate climate in reference to cultural engagement in educational development programs, giving URF a forum. This approach has a direct impact on equity and inclusion not only for racially minoritized students but also for BLF. 


\section{Design and Data Collection}

A qualitative single case study method generated an in-depth, multifaceted understanding of the experiences of BLF. Data were collected in the form of two semi-structured interviews, participant journaling, and collection of institutional information and texts. The research took place at an academic medical center/school of medicine located in the Midwest region of the United States (MSOM) and was approved by the institution's review board. Participants included eight BLF across the ranks of assistant, associate and full professors, self-identified as four women and four men. To keep responses anonymous, participants are referred to with pseudonyms. The faculty answered questions related to their socialization, mentoring, faculty development, institutional climate, and diversity and inclusion.

\section{Analysis}

An IE scorecard was used to organize and code the information under each theme. Its dimensions included the following units: external environment, organizational behavior, organizational culture, and change strategy (AAC\&U, n.d.) For example, change strategy, defined as institutional strategy to make diversity and inclusion part of the organization, included components regarding senior leadership vision and buyin, capacity building, and leveraging resources. The scorecard was critical in demonstrating how each element under this IE organizational framework may influence faculty development for BLF. IE guided the analysis of the experiences and institutional environment of BLF in medicine. Using IE helped give a clear view of the organization and enabled analysis of the underlying experiences of BLF with faculty development (see Appendix A: Scorecard). 


\section{Findings and Discussion}

The majority of participants in this study obtained their faculty development through professional organizations or equivalent networks. They spoke positively about their institution's offerings and faculty developers' work at their own institution. However, some participants also referred to these opportunities as majority- or dominant groupcentric and reported that, at times, these opportunities did not speak directly to their experiences as BLF. They also reported the lack of a critical mass of BLF mentors and role models at their institution as well as the need for tailored faculty development.

One participant, Henok, summarized successful efforts made in the faculty development and advancement of women in academic medicine in comparison to those of BLF: "Men now get it for women, but men and women still don't get it for faculty of color." Progress for women has been advanced through faculty development initiatives at national, regional, and localized settings. While the field of academic medicine continues to make significant progress for women in the academy, it has not been able to achieve the same for BLF.

For example, prestigious faculty development programs include the Executive Leadership for Academic Medicine (ELAM) at Drexel University. ELAM "offers an intensive one-year fellowship of leadership training with extensive coaching, networking and mentoring opportunities aimed at expanding the national pool of qualified women candidates for leadership in academic medicine, dentistry, public health and pharmacy" (Drexel University, n.d.-a). Other examples include the Rudi Ansbacher Advancing Women in Academic Medicine Leadership Scholars Program at the University of Michigan, an intensive 18-month leadership development program designed to accelerate the development of women for senior positions in academic medicine and health care (University of Michigan, n.d.). The Higher Education Resource Services (HERS) Leadership Institute offers programs that support women through different career stages (see https://www.hersnetwork.org). Lastly, the Association for American 
Medical Colleges (AAMC) is one of the few organizations that offers faculty development programs for early- and mid-career women and underrepresented faculty in academic medicine (see https://www.aa mc.org).

URF from minoritized racial/ethnic backgrounds continue to feel "left behind" when it comes to diversity initiatives and faculty advancement. The study found two major themes related to BLF experience with faculty development: the expressed need for tailored faculty development for URF and faculty development as a pathway for networking.

\section{Tailored Faculty and Educational Development}

Participants expressed the importance of educational development programs. For example, Elizabeth stated,

The first thing that comes to mind is how to be a better teacher for the students. I cannot say that I have had formal training in that at all. I have listened to people talk about how their training programs even had them taking some courses on teaching at different levels, and I have not had any of that. Yet I am teaching. So, I think something along those lines would be really, really useful to be able to maximize what it is that I can offer to the students, to make sure I give them all that they need.

Participants also highlighted a necessary distinction in what BLF need. Participants reported a desire to encourage fellow BLF to attend as many faculty development opportunities as possible and also charge the institutional leadership with creating programs tailored to them. For example, Blair noted,

I think the information is useful across the board, but what's missing is that individual touch. Because the one thing that we're really afraid of saying out loud in front of other people is, "Am I really good enough?" 
And that's something that you [are] just not going to get to when you're in a (general) faculty development program. When you take off the morning and you go listen to people say, "Okay, you need more writing, here's how you write a grant," all of that is helpful. But what I think I found is the most helpful was somebody kind of sitting me down and go, "You are smart. Screw what those other folks say."

Evelio seconded this sentiment in regard to general programs:

It was informative in terms of what the policies are, how to navigate through the system and navigate in terms of, for promotion. But they could not relate, since they were the majority, of how a minority [sic] orchestrates through our challenges ... There should be some things with minority $[\mathrm{sic}]$. There should be an organized pathway or system for faculty that should be based upon the generic everyone else. But, there needs to be some other added focus for minorities and that minority [sic] is based upon race, based upon sex. There needs to be some little added things, opportunities are very different and the challenges we go through are very different . . . I do think it is very important for someone to get to their comfort level, their comfort zone. And for me, I would've been more comfortable if there was more people like me.

This quote suggests that tailored BLF educational development is challenging because it requires an understanding of the fact that BLF experiences are different from those of the majority, including but not limited to isolation, racism, discrimination, credibility challenged, and lower student evaluations. Faculty developers and institutional leaders need to acknowledge that these experiences contribute to limited numbers of BLF. Furthermore, limited faculty diversity may very well be the reason for structural barriers to institutional change. Lack of faculty diversification is concerning, and it is time to dedicate more resources and spaces for the development of BLF.

As BLF doubted a diversity commitment, they were also reminded 
that their institution's priorities may not include them. Addressing what MSOM specifically offered for BLF in terms of their development, Jessika stated, "I don't think it's like from neglect, I just think that it may not even be ... It's just not in the forefront." In fact, Alberto highlighted his own doubts about the potential to his own career. He stated, "The first time that I actually heard about the importance of these programs, I had a partial administrative appointment. Perhaps my own fault, but I didn't have anyone say prior to that 'This would be good for you.' 'This would benefit you.'"

Although BLF participants attended events offered by MSOM faculty developers, they reported that it was not necessarily a space in which they felt comfortable or in which facilitators realized that there were complex identities at stake. Jessika specifically spoke about these complexities in terms of tailoring opportunities:

I was just really mindful of the ways, of the additional complexities that come as sort of being a woman of color and the ways some of the issues are very much the same, and some of them aren't. And I think that that notion of tailoring of tools and resources, I guess at first I wouldn't expect for people to be aware of it, the necessity even, but it is a felt absence in some settings.

Based on BLF perspectives, educational development programs might also require and benefit from the presence of senior URF or BLF who could contribute to the process; however, implementation of such a system would be difficult considering the limited number of URF or BLF.

The presence of senior BLF opens a range of possibilities for earlycareer BLF, offering mentors to look up to, the example of someone who was able to achieve the next faculty rank and with whom they may share similar experiences by virtue of operating in the same environment. BLF educational development programs have great potential for contributing to not only promotion and tenure but also networking, relationship building, accountability, and affirmation spaces. 


\section{Faculty and Educational Development as Networking, Accountability, and Affirmation Spaces}

Participants in this study spoke about their own development, either through their institution or professional organizations, and reported that they found external opportunities to provide what was lacking at their local institution. External development programs offered additional networking opportunities with other BLF in the field, as BLF at individual institutions were often few. As Jessika reported,

So it [the external program] has been a place to make great connections . . . and I guess networking. It feels like not a sufficient enough term, because it's really been this place to really develop relationships and to also gain some degree of notoriety, some grand rounds and invitation come out of that and I think connections with people across institutions.

As part of targeted development opportunities through a professional organization, participants have been able to keep in touch with other BLF nationwide. In lieu of a robust institutional network, participants have been able to hold one another accountable throughout their career progress through collaborations and sponsorship. They spoke about this type of program as an eye-opener in that it affirmed their realities and similar experiences. Francisco expressed,

They talk about the same things [experiences], because most were in the same boat, same level, and then you could see that it [our experiences] was all true or reality. ... Affirmation about the differences even those I did not see before. I realize that they were real.

Participation has not only increased their professional network but also created prospects for holding one another accountable, sharing opportunities, and creating champions nationwide.

Rosana was able to find a home in her professional organization. By 
having this space for networking, relationship building, and accountability, she found opportunities in both her own institution and other organizations. She was able to realize that there was a place for her development. A few participants discovered a critical mass of people with a shared commitment and concerns around advancing BLF (and trainees) at their institution. Jessika spoke of the need for synergies and opportunities for convening BLF talent and for the relational component of development that affirms, "you're not the only one here with those passions, interests, and concerns." Educational development seems to provide an additional space for networking but also a space where BLF can feel affirmation, especially when surrounded by other BLF talent.

Whereas faculty development has made great strides for women in medicine and science by creating spaces for them, spaces developed for BLF are still limited. BLF participants in this study looked for more supportive and effective professional networks. They suggested that faculty and educational development cannot be generalized in ways that would benefit all faculty, all tracks, and all subgroups. Based on the findings of this study, BLF value spaces that bring them together and in which they can speak about their accomplishments, barriers, challenges, and opportunities in the academy. The best model would also avoid alienation from general programming and would provide parallel spaces in which to explore underrepresented and minoritized narratives. This represents the need for an IE environment.

Tuitt (2010) proposed inclusive practices in six tenets: highlighting unique cultural characteristics as an asset to the institution, being aware of unique experiences and challenges, ensuring support and resources, committing to diversity and excellence, paying attention to BLF culture and climate, and serving as allies. For example, Henok not only wants his cultural background to be highlighted, but he also would like his work to be recognized as an asset to the institution:

In terms of the value. It's this idea that when I look at my CV, it is hard not to say, "Damn, this guy is good." I know of a lot of universities that 
would just kill to have somebody with my background, being as successful. To see that they're not even trying to highlight it. It's just odd to me. That I get this huge grant, and I tell the news, whatever. They don't even get back to me. I don't think they are even thinking about ... regardless of whether I'm a minority [sic] in their eyes.

Furthermore, Henok noted two common requests institutions make of BLF: special committees and pictures. In efforts to demonstrate a commitment to diversity and inclusion, BLF feel they are only remembered in these two instances.

We can say, "Hey, look." We don't have to say it but, "Look, we have a diverse faculty." It's like when I was in $\mathrm{X}$; every freaking year, I would be called for pictures for the catalog. I said, "No, I'm not going to do it." We don't have more faculty of color. "I'm not going to do it." I'm not going to be your token. That's the only time they remember you. "Oh, we need somebody at the diversity council; HR says that this committee has to be diverse." That's the only time that they look for you. It is the same thing with women.

In support of BLF development, BLF highlighted the importance of having a space with individuals sharing similar backgrounds, or cultural familiarity. BLF faculty development spaces encouraged participants to share experiences, perspectives, and ideas centered on individuals' cultural identities while strengthening diversity with cross-cultural work.

BLF participants firmly conveyed what such programs and spaces really do for them in four ways. First, BLF made it clear that there is great value in tailored educational development programs. These programs create a space for networking, relationship building, accountability, and, perhaps most importantly, affirmation. Second, BLF benefit from accountability partners: colleagues who follow up on their progress, colleagues who seek collaboration, and colleagues who bring forward opportunities. Third, BLF need opportunities to share 
their experiences, perspectives, barriers, and challenges. Furthermore, BLF-targeted programs can be the only space that affirms that microaggressions, discrimination, and overt racism are not imaginary. Tailored programs need to acknowledge the unique experiences of BLF while also recognizing their important contributions in advancing medicine and science. Fourth, BLF need to build institutional networks by building relationships with individuals who will become champions for their work.

Implications for practice are numerous. It is important to acknowledge the challenges in implementing these tailored educational development programs, including resource allocation, staffing, and expertise. Although this study clearly suggests the importance of tailored programs, practitioner scholars may enhance current offerings by including time and spaces for BLF to address specific topics and issues within the framework of an institution's current programming. For example, educational development sessions may speak to the realities of student evaluations as gendered and racialized. Promotion and tenure sessions can speak about the extra burden of BLF service to the institution; developers can also name cultural taxation and structural barriers to advancement. Effective models may simply practice cultural relevance, along with embedding cultural humility and IE. These suggestions go beyond academic medicine and can be instituted broadly in higher education.

\section{Conclusion}

This study highlighted the need for academic medicine to sponsor faculty and educational development of Black and Latinx faculty. Furthermore, as practitioners and scholars, we need to be more attentive to higher education and academic medicine culture, climate, and overall environment, which have a significant impact on Black and Latinx faculty. In providing the tools for scholarship of teaching and learning (SoTL), educational development, and career development, 
developers must understand underrepresented faculty experiences without risking further minoritization. This support can be delivered through these key programs. The fields of higher education and academic medicine need more thoughtful and reinvigorating messages as well as effective practices in support of equity, diversity, and inclusion.

\section{Biography}

Dr. Sylk Sotto-Santiago is the Vice Chair for Faculty Affairs, Development, and Diversity and an Assistant Professor in the Department of Medicine at Indiana University School of Medicine (IUSM). Her scholarship and research centers on (in)equity and inclusion and includes faculty affairs and professional/educational development, STEM/medical education, organizational leadership, and health equity. She serves institutional committees and co-chairs IUSM's Diversity Council. At the national level, Dr. Sotto-Santiago is involved in various organizations serving higher education and academic medicine communities.

\section{References}

Arbuckle, J., \& Williams, B. D. (2003). Students' perceptions of expressiveness: Age and gender effects on teacher evaluations. Sex Roles, 49, 507-516. https://doi.org/10.1023/A:1025832707002

Association of American Colleges \& Universities. (n.d.). Making excellence inclusive. Retrieved December 13, 2018, from https://www.aacu.org/maki ng-excellence-inclusive

Barrett, D. J. (2008). The evolving organizational structure of academic health centers: The case of the University of Florida. Academic Medicine, 83(9), 804-808. https://doi.org/10.1097/ACM.0b013e318181d054

Bergen, S. S., Jr. (2000). Underrepresented minorities in medicine. JAMA: The Journal of the American Medical Association, 284(9), 1138-1139. https:// doi.org/10.1001/jama.284.9.1138

Campbell, K. M., \& Rodríguez, J. E. (2013). Minority faculty face challenges similar to those of minority college students. Academic Medicine, 88(8), 1056-1057. https://doi.org/10.1097/ACM.0b013e318299265b 
Cohen, J. J. (1998). Time to shatter the glass ceiling for minority faculty. JAMA: The Journal of the American Medical Association, 280(9), 821-822. https:// doi.org/10.1001/jama.280.9.821

Cole, T. R., Goodrich, T. J., \& Gritz, E. R. (2009). Faculty health in academic medicine: Physicians, scientists, and the pressures of success. Humana Press.

Cropsey, K., Masho, S., Shiang, R., Sikka, V., Kornstein, S., Hampton, C., \& Committee on the Status of Women and Minorities, Virginia Commonwealth University School of Medicine, Medical College of Virginia Campus. (2008). Why do faculty leave? Reasons for attrition of women and minority faculty from a medical school: Four-year results. Journal of Women's Health, 17(7), 1-8.

Daley, S. P., Broyles, S. L., Rivera, L. M., Brennan, J. J., Lu, E. R., \& Reznik, V. (2011).

A conceptual model for faculty development in academic medicine: The underrepresented minority faculty experience. Journal of the National Medical Association, 103(9-10), 816-821. https://doi.org/10.1016/S0027 -9684(15)30435-1

Daufin, E. (2001). Minority faculty job experience, expectations, and satisfaction.

Journalism \& Mass Communication Educator, 56(1), 18-30. doi:10.1177/1077 69580105600103

Drexel University. (n.d.-a). About ELAM-College of Medicine. Retrieved December 13, 2018 from https://drexel.edu/medicine/academics/wome ns-health-and-leadership/elam/about-elam/

Drexel University. (n.d.-b). Ensuring a welcoming and inclusive environment at Drexel University. Retrieved December 13, 2018 from\%20http://drexel .edu/oed/diversity/overview/

Griffin, K. A., \& Reddick, R. J. (2011). Surveillance and sacrifice: Gender differences in the mentoring patterns of Black professors at predominantly White research universities. American Educational Research Journal, 48(5), 1032-1057. https://doi.org/10.3102/0002831211405025

Guevara, J. P., Adanga, E., Avakame, E., \& Carthon, M. B. (2013). Minority faculty development programs and underrepresented minority faculty representation at US medical schools. JAMA: The Journal of the American Medical Association, 310(21), 2297-2304. https://doi.org/10.1001/jama .2013 .282116

Harlow, R. (2003). "Race doesn't matter, but . . .": The effect of race on professors' experiences and emotion management in the undergraduate college classroom. Social Psychology Quarterly, 66(4), 348-363. https://doi.org/10 $.2307 / 1519834$ 
Hartlep, N., \& Ball, D. (2019). Racial battle fatigue in faculty: Perspectives and lessons from higher education. Routledge.

Irby, D. M., \& Wilkerson, L. (2003). Educational innovations in academic medicine and environmental trends. Journal of General Internal Medicine, 18, 370-376. https://doi.org/10.1046/j.1525-1497.2003.21049.x

Jayakumar, U., Howard,, T. Allen, W., \& Han, J. (2009). Racial Privilege in the professioriate: An Exploration of Campus Climate, Retention, and Satisfaction. Journal of Higher Education (80)5, 538-563.

Laden, B. V., \& Hagedorn, L. S. (2000). Job satisfaction among faculty of color in academe: Individual survivors or institutional transformers? New Directions for Institutional Research, 2000(105), 57-66. https://doi.org/10.1002 /ir.10505

Palmer, M. M., Dankoski, M. E., Smith, J. S., Brutkiewicz, R. R., \& Bogdewic, S. P. (2011). Exploring changes in culture and vitality: The outcomes of faculty development. The Journal of Faculty Development, 25(1), 21-27.

Pololi, L., Kern, D. E., Carr, P., Conrad, P., \& Knight, S. (2009). The culture of academic medicine: Faculty perceptions of the lack of alignment between individual and institutional values. Journal of General Internal Medicine, 24, 1289-1295. https://doi.org/10.1007/s11606-009-1131-5

Pololi, L. H., Krupat, E., Civian, J. T., Ash, A. S., \& Brennan, R. T. (2012). Why are a quarter of faculty considering leaving academic medicine? A study of their perceptions of institutional culture and intentions to leave at 26 representative U.S. medical schools. Academic Medicine, 87(7), 859-869. https://doi.org/10.1097/acm.0b013e3182582b18

Rodríguez, J. E., Campbell, K. M., Fogarty, J. P., \& Williams, R. L. (2014). Underrepresented minority faculty in academic medicine: A systematic review of URM faculty development. Family Medicine, 46(2), 100-104.

Salazar, M. D. C., Norton, A. S., \& Tuitt, F. A. (2010). 12: Weaving promising practices for inclusive excellence into the higher education classroom. To Improve the Academy, 28(1), 208-226. https://doi.org/10.1002/j.2334-48 22.2010.tb00604.x

Social Sciences Feminist Network Research Interest Group. (2017). The burden of invisible work in academia: Social inequalities and time use in five university departments. Humboldt Journal of Social Relations, 39, 228-245.

Sotto-Santiago, S., Tuitt, F., \& Saelua, N. (2019). All faculty matter: The continued search for culturally relevant practices in faculty development. The Journal of Faculty Development, 33(3), 83-93.

Sotto-Santiago, S. (2019). Time to reconsider the word minority in academic medicine. Journal of Best Practices in Health Professions Diversity, 12(1), 72-78.

To Improve the Academy • Vol. 39, No. 2 • Fall 2020 
Sprague, J., \& Massoni, K. (2005). Student evaluations and gendered expectations: What we can't count can hurt us. Sex Roles, 53(11), 779-793. https:// doi.org/10.1007/s11199-005-8292-4

Stanley, C. A. (2006a). Coloring the academic landscape: Faculty of color breaking the silence in predominantly white colleges and universities. American Educational Research Journal, 43(4), 701-736.

Stanley, C. A. (Ed.). (2006b). Faculty of color: Teaching in predominantly white colleges and universities. Anker Publishing.

Steele, C., \& Aronson, J. (1995). Stereotype threat and the intellectual test performance of African Americans. Journal of Personality and Social Psychology, 69(5), 797-811.

Thompson, G. L., \& Louque, A. C. (2005). Exposing the "culture of arrogance" in the academy: A blueprint for increasing Black faculty satisfaction in higher education. Stylus Publishing.

Tierney, W. G., \& Rhoads, R. A. (1993). Enhancing promotion, tenure and beyond: Faculty socialization as a cultural process (ASHE-ERIC Higher Education Reports, 6). Association for the Study of Higher Education.

Trower, C., \& Chair, R. , (2002). Faculty Diversity: Too Little for Too Long. Harvard Magazine 104:33.

Tuitt, F. (2010). Working with underrepresented faculty. In K. J. Gillespie \& D. L. Robertson (Eds.), A guide to faculty development (pp. 225-242). Jossey-Bass.

Tuitt, F., Hanna, M., Martínez, L. M., Salazar, M. D. C., \& Griffin, R. (2009, Fall). Teaching in the line of fire: Faculty of color in the academy. Thought and Action, 65-74.

Turner, C., Myers, S., \& Creswell, J. (1999). Exploring underrepresentation the case of faculty of color in the midwest. Journal of HigherEducation, 70(1), 27-59.

University of Denver. (n.d.). Inclusive excellence at DU. http://www.du.edu /cme/resources/inclusive-excellence.html

University of Michigan. (n.d.). Advancing women in academic medicine. Retrieved December 13, 2018, from https://faculty.medicine.umich.edu/fa culty-career-development/programs-awards/advancing-women-academic -medicine

Virginia Commonwealth University. (n.d.). Inclusive excellence. Retrieved December 13, 2018, from \%20https://inclusive.vcu.edu 


\section{Appendix A}

\section{Adaptation of Inclusive Excellence Organizational Change Scorecard}

\begin{tabular}{|c|c|c|c|}
\hline Elements & Definition & Components & Faculty perspectives \\
\hline $\begin{array}{l}\text { External } \\
\text { environment }\end{array}$ & $\begin{array}{l}\text { Environmental forces } \\
\text { that drive and con- } \\
\text { strain implementa- } \\
\text { tion of diversity and } \\
\text { inclusion offices, } \\
\text { initiatives, and pro- } \\
\text { grams }\end{array}$ & $\begin{array}{l}\text { Shifting demograph- } \\
\text { ics } \\
\text { Societal inequities } \\
\text { Workforce needs } \\
\text { Political and legal } \\
\text { dynamics in the } \\
\text { state }\end{array}$ & $\begin{array}{l}\text { How each element } \\
\quad \text { affects each subunit? } \\
\text { Diversity and inclusion } \\
\text { Acad med culture } \\
\text { Institutional climate } \\
\text { Socialization } \\
\text { Mentorship } \\
\text { Professional develop- } \\
\quad \text { ment }\end{array}$ \\
\hline $\begin{array}{l}\text { Organizational } \\
\text { behavior } \\
\text { dimensions }\end{array}$ & $\begin{array}{l}\text { Multiple vantage } \\
\text { points that must be } \\
\text { used to shift the } \\
\text { informal and formal } \\
\text { environmental } \\
\text { dynamics toward } \\
\text { inclusive excellence }\end{array}$ & $\begin{array}{l}\text { Systemic } \\
\text { bureaucratic- } \\
\text { office/organiza- } \\
\text { tional/departmental } \\
\text { and leadership } \\
\text { structure }\end{array}$ & $\begin{array}{l}\text { How each element } \\
\text { affects each subunit? }\end{array}$ \\
\hline $\begin{array}{l}\text { Organizational } \\
\text { culture }\end{array}$ & $\begin{array}{l}\text { Dynamics that define } \\
\text { higher education } \\
\text { and that must be } \\
\text { navigated to } \\
\text { achieve IE }\end{array}$ & $\begin{array}{l}\text { Mission } \\
\text { Vision } \\
\text { Values } \\
\text { Traditions and norms } \\
\text { (spoken and unspo- } \\
\text { ken) }\end{array}$ & $\begin{array}{l}\text { How each element } \\
\text { affects each subunit? }\end{array}$ \\
\hline IE scorecard & $\begin{array}{l}\text { Understanding IE that } \\
\text { extends and adapts } \\
\text { work on diversity } \\
\text { and dimensions of } \\
\text { the campus climate }\end{array}$ & $\begin{array}{l}\text { Access and equity } \\
\text { diversity in the for- } \\
\text { mal and informal } \\
\text { campus climate }\end{array}$ & $\begin{array}{l}\text { How each element } \\
\text { affects each subunit? }\end{array}$ \\
\hline IE change strategy & $\begin{array}{l}\text { Fluid institutional } \\
\text { strategy to make IE } \\
\text { a core capability of } \\
\text { the organization }\end{array}$ & $\begin{array}{l}\text { Senior leadership } \\
\text { vision and buy-in } \\
\text { Capacity building } \\
\text { leveraging } \\
\text { resources }\end{array}$ & $\begin{array}{l}\text { How each element } \\
\text { affects each subunit? }\end{array}$ \\
\hline
\end{tabular}




\section{Example:}

\begin{tabular}{|c|c|c|c|}
\hline Elements & $\begin{array}{c}\text { Faculty perspectives- } \\
\text { professional } \\
\text { development }\end{array}$ & Quotes & Memo \\
\hline $\begin{array}{l}\text { External } \\
\text { environment }\end{array}$ & $\begin{array}{l}\text { National/professional } \\
\text { organizations } \\
\text { External influences } \\
\text { Dynamics of/about } \\
\text { minoritized groups in } \\
\text { the state }\end{array}$ & & \\
\hline $\begin{array}{l}\text { Organizational } \\
\text { behavior dimen- } \\
\text { sions }\end{array}$ & $\begin{array}{l}\text { Institution's faculty and } \\
\text { educational } \\
\text { - development } \\
\text { —developers ( \& train- } \\
\text { ing) } \\
\text {-office } \\
\text { - programming } \\
\text { - leadership support }\end{array}$ & & \\
\hline $\begin{array}{l}\text { Organizational } \\
\text { culture }\end{array}$ & $\begin{array}{l}\text { Academic medicine } \\
\text { culture } \\
\text { Departmental climate } \\
\text { DEIJ mission } \\
\text { Customary/standard } \\
\text { processes/ proce- } \\
\text { dures, policies (i.e., } \\
\text { P\&T) }\end{array}$ & & \\
\hline IE scorecard & $\begin{array}{l}\text { Institutional climate } \\
\text { Hidden curricula/mes- } \\
\text { sages } \\
\text { Status of minoritized } \\
\text { faculty and students }\end{array}$ & & \\
\hline IE change strategy & $\begin{array}{l}\text { Leadership support and } \\
\text { vision } \\
\text { Funds flow }\end{array}$ & & \\
\hline
\end{tabular}

To Improve the Academy • Vol. 39, No. 2 • Fall 2020 